\title{
A Volatilidade da Arquitetura Comercial sob a influência do comercio online e da sinestesia
}
The Volatility of Commercial Architecture under the Influence of Online Commerce and Synesthesia
La volatilidad de la arquitectura comercial bajo la influencia del comercio online y la sinestesia

\author{
Gabriele Cristina Santos Silva \\ Graduanda, IASCJ, Brasil \\ gabrielecrsilva@gmail.com \\ Tatiana Ribeiro de Carvalho \\ Professora Mestra, IASCJ, Brasil \\ Tatiana.carvalhoarquit@gmai.com
}




\title{
Revista Científica ANAP Brasil
}

\author{
ISSN 1984-3240 - Volume 14, número 33, 2021
}

\section{RESUMO}

A presente pesquisa explora a arquitetura comercial e as mudanças ocorridas neste setor devido a pandemia do Covid 19 - que intensificou o comercio online - e a intensificação da arquitetura sinestésica aplicado a arquitetura comercial, como fatores que têm influenciado diretamente na qualidade e configuração dos espaços comerciais. Para melhor conceituar a pesquisa será realizada uma investigação acerca das formas de comércio, desde os primórdios até a atualidade, explorando o advento das tradicionais lojas de rua, shoppings centers assim como conceitos recentes: visual merchandising, lojas conceito, pontos de venda, culminando no comércio online. O objetivo é realizar um percurso histórico- investigativo no sentido de entender, fomentar a discussão e analisar como o setor comercial tem estimulado o público-alvo e atraído novos consumidores diante das atuais mudanças no setor, assim como traçar possíveis cenários futuros/tendências frente às mudanças pelas quais a sociedade está passando. A pesquisa se desenvolve a partir de pesquisas bibliográficas, bem como pesquisas em artigos, teses, material online para melhor compreensão de conceitos e entendimento temporal das práticas de comércio adotada ao longo do tempo.

PALAVRAS-CHAVE: Sinestesia. Arquitetura Comercial. Covid-19.

\section{ABSTRACT}

The present research explores the commercial architecture and the changes that have occurred in this sector due to the Covid 19 pandemic - which intensified online commerce - and the intensification of the synesthetic architecture applied to commercial architecture, as factors that have directly influenced the quality and configuration of commercial spaces. To better conceptualize the research, an investigation will be carried out about the forms of commerce, from the beginning to the present day, exploring the advent of traditional street stores, shopping malls as well as recent concepts: visual merchandising, concept stores, points of sale, culminating in online commerce. The objective is to conduct a historical and investigative course in order to understand, foster discussion, and analyze how the commercial sector has stimulated the target audience and attracted new consumers in face of the current changes in the sector, as well as to outline possible future scenarios/trends in face of the changes society is going through. The research is developed from bibliographic research, as well as research in articles, theses, and online material for a better understanding of concepts and temporal understanding of commerce practices adopted over time.

KETWORDS: Synesthesia. Commercial Architecture. Covid-19.

\section{RESUMEN}

La presente investigación explora la arquitectura comercial y los cambios ocurridos en este sector debido a la pandemia del Covid 19 -que intensificó el comercio online- y la intensificación de la arquitectura sinestésica aplicada a la arquitectura comercial, como factores que han influido directamente en la calidad y configuración de los espacios comerciales. Para conceptualizar mejor la investigación se realizará una investigación sobre las formas de comercio, desde los primeros tiempos hasta la actualidad, explorando el advenimiento de las tiendas tradicionales de calle, los centros comerciales así como los conceptos recientes: visual merchandising, concept stores, puntos de venta, culminando en el comercio online. El objetivo es realizar un recorrido histórico y de investigación en el sentido de comprender, fomentar el debate y analizar cómo el sector comercial ha estimulado al público objetivo y atraído a nuevos consumidores a la luz de los cambios actuales en el sector, así como esbozar posibles escenarios/tendencias futuras a la luz de los cambios que está experimentando la sociedad. La investigación se desarrolla a partir de la investigación bibliográfica, así como la investigación en artículos, tesis y material en línea para una mejor comprensión de los conceptos y la comprensión temporal de las prácticas comerciales adoptadas en el tiempo.

CONTRASENAS: Sinestesia. Arquitectura comercial. Covid-19. 


\section{Revista Científica ANAP Brasil}

ISSN 1984-3240 - Volume 14, número 33, 2021

\section{INTRODUÇÃO}

Esta pesquisa se propõe a explorar a configuração da arquitetura comercial com vistas a investigar as mudanças ocorridas no setor - referente a intensificação do comercio online e da sinestesia, como fatores que revelaram a volatilidade do setor e apontam a necessidade de adequação deste às demandas vivenciadas pela sociedade na atualidade.

O primeiro ponto que se coloca - referente à arquitetura comercial e que e tem causado grandes transformações nesta área - diz respeito a pandemia do SARS-CoV-2, que tem intensificando ainda mais um processo que já estava em progresso: o comercio online.

Devido à alta transmissibilidade do vírus - amplamente divulgada, discutida e analisada em vários países do mundo - especialistas da saúde pública passaram a recomendar a implementação de medidas no combate à pandemia. Dentre essas medidas o distanciamento social foi apontado como prerrogativa essencial ao controle da disseminação do vírus.

Como reflexo das medidas de distanciamento, o convívio social, a vida em sociedade, assim como a questão comercial, tem sido esferas impactadas diretamente. Diante das novas prioridades, restrições, e parâmetros de segurança, a sociedade tem buscado se adaptar a esta nova realidade como revela a (Figura 1).

Figura 1 - Manchete site de notícias sobre interação social

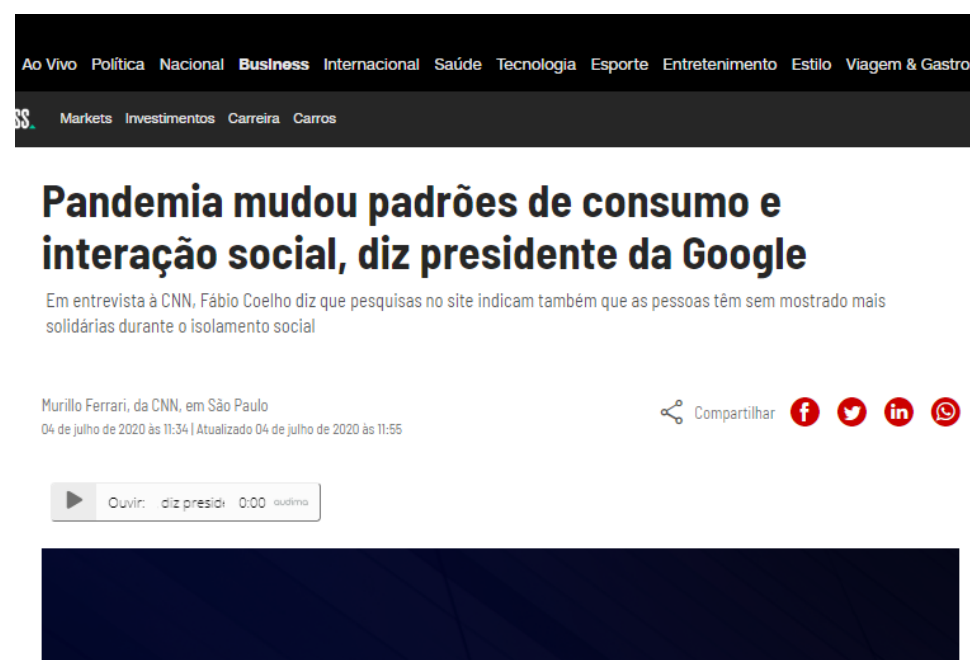

Fonte: Ferrari, 2020

A manchete acima aponta o setor que será aqui investigado, a arquitetura comercial, assim como as mudanças ocorridas no setor devido à pandemia.

Em uma entrevista para o Instituto de Ensino e Pesquisa (INSPER), Farah Diba Abrantes-Braga, professora e pesquisadora, também analisa o comportamento das marcas em mídias sociais diante deste novo cenário da pandemia e salienta:

A crise mundial da Covid-19 não somente demandou isolamento por parte da população, aumentando assim o tempo de interação nas mídias sociais, como também forçou marcas e seus negócios a irem para o on-line sob a ameaça de não sobreviverem. (INSPER, 2020).

Diante deste novo cenário, novas posturas e comportamentos tem sido verificado 


\title{
Revista Científica ANAP Brasil
}

ISSN 1984-3240 - Volume 14, número 33, 2021

como mostra um estudo feito pela Associação Brasileira de Comercio Eletrônico (ABComm, 2020), realizado nos primeiros oito meses de 2020. Tal estudo mostrou que surgiram mais de 135 mil novas lojas virtuais neste setor, o que corresponde a um aumento de $56,8 \%$.

Neste sentido também, Cruvinel (2020), atesta que as vendas - antes majoritariamente realizadas em lojas físicas e com atendimento presencial ao cliente - tiveram que migrar, de forma abrupta, para um ambiente virtual.

Diante disso notou-se uma movimentação no setor no sentido de buscar alternativas para se adequar a esta mudança.

Outro ponto que tem afetado também a arquitetura comercial é a sinestesia, como esclarece Plaza (2003, p. 46):

\begin{abstract}
A palavra "sentidos" é tão enganosa quanto o conceito de "sensação", pois não existem sentidos departamentalizações, mas sinestesia como inter-relação de todos os sentidos. A sinestesia, como sensibilidade integrada ao movimento e inter-relação dos sentidos, garante-nos a apreensão do real.
\end{abstract}

Posto isso nota-se que o ser humano, ao adentrar qualquer ambiente, está atribuindo um juízo de valor ao espaço de forma completa pois está, de maneira ampla, experimentando e vivenciando o espaço circundante.

A arquitetura comercial está ligada diretamente à sinestesia como sendo um caminho de persuadir e induzir o cliente à efetivação da compra. Desta forma muita atenção tem sido dada a aplicação da sinestesia à arquitetura comercial que tem se mostrado como setor bastante fértil para atuação de arquitetos e urbanistas. Por essa razão se faz relevante ressaltar o perfil do profissional, arquiteto e urbanista, como explica o (CONSELHO NACIONAL DE EDUCAÇÃO, 2010, p. 1-2) que delineia o perfil do egresso deste curso:

[...] profissionais generalistas, capazes de compreender e traduzir as necessidades de indivíduos, grupos sociais e comunidade, com relação à concepção, à organização e à construção do espaço interior e exterior, abrangendo o urbanismo, a edificação, o paisagismo, $[\ldots]$

Em concordância com o exposto acima, nota-se que segundo o Manual do Conselho de Arquitetura e Urbanismo (CAU, 2016), o Arquiteto e Urbanista projeta tanto ambientes interiores quanto exteriores, e que este profissional é visto como um instrumento social, uma vez que está voltado a atender às aspirações humanas, seja modificando, criando, adaptando, ambientes - internos ou externos - mas sempre com vistas a tornar o local de intervenção, um ambiente habitável, confortável, equilibrado, belo e que vá de encontro, as expectativas dos seus clientes e demandas que permeiam a sociedade - contexto social, econômico, tecnológico no qual a sociedade está inserida..

Veríssimo (2009) também nos explica que o arquiteto já conhece o projeto antes dele se apresentar num corpo físico e que o momento de apresentação deste é sempre uma revelação surpreendente, pois quando o projeto passa a existir, a arquitetura se revela aos sentidos de quem a projetou, permitindo enfim ser percebido e vivenciado por outras pessoas.

Essa revelação, como salienta Veríssimo (2009), pode, segundo Athens (2009), impactar o humor e ter influência inclusive na saúde e bem-estar das pessoas. Diante disso percebe-se que a relação entre psicologia, arquitetura e sinestesia é estreita.

Analisando estas considerações, torna-se evidente que o setor comercial tem se 


\section{Revista Científica ANAP Brasil}

ISSN 1984-3240 - Volume 14, número 33, 2021

mostrado volátil e sujeito às adaptações constantes, que por sua vez, estão atreladas diretamente às demandas da sociedade. Por essa razão, a arquitetura comercial será aqui abordada mais detalhadamente.

\section{OBJETIVOS}

Os objetivos a seguir conduzirão a pesquisa, como segue:

\subsection{Objetivo geral}

À guisa de um entendimento acerca da nova realidade do comercio online e sua intensificação devido a pandemia, esta pesquisa objetiva fomentar a discussão e entendimento acerca dos novos cenários: o avanço do setor referente ao comércio online - intensificado sobremaneira em decorrência da pandemia do COVID 19 - e a ascensão da arquitetura sinestésica no setor comercial. Objetiva-se com isso traçar possíveis tendências para o setor diante desta nova realidade.

\subsection{Objetivos específicos}

- Explorar e explanar de maneira sucinta as formas de comércio desde seus primórdios até os tempos atuais;

- Investigar os efeitos da pandemia no setor e pontuar as tendências frente à esta nova realidade;

- Entender o que é sinestesia e sua importância para o setor comercial;

\section{MÉTOdOS DE ANÁLISE}

Para a fundamentação deste projeto serão necessárias pesquisas bibliográficas, pesquisas em artigos, teses, internet para melhor compreensão do setor comercial frente a arquitetura sinestésica, assim como levantamento das recentes transformações do setor relacionadas a pandemia: o comercio online.

\subsection{Breve histórico da arquitetura comercial: primórdios e sua importância}

É sabido que as trocas comerciais foram de suma importância para o desenvolvimento da vida em sociedade e também para a economia.

Para melhor entendimento o termo comercio é importante esclarecer que este termo se refere a uma atividade socioeconômica que consiste na compra, troca ou venda de bens, mercadorias seja para usufruto próprio, venda ou suas transformações. (COMÉRCIO, 2019).

$\mathrm{Na}$ antiguidade as trocas de produtos eram conhecidas como escambo como ressalta Conde, Mafra e Cappelle (2014), que explica que o escambo se baseava na troca de serviços ou mercadorias que ocorriam sem a utilização de qualquer tipo de recurso monetário, inclusive de moeda. 


\section{Revista Científica ANAP Brasil}

ISSN 1984-3240 - Volume 14, número 33, 2021

Sobre as trocas Leal (2014) nos diz que estas surgiram entre os grupos primitivos, no intuito de satisfazer suas necessidades biológicas de sobrevivência, e que essa prática deu origem às primeiras noções de comércio, intercâmbio cultural e divisão de trabalho.

Ao longo da história da humanidade, outros momentos revelam a importância do comercio, como ressalta De Moura (2008), que afirmou que os romanos, por exemplo, travaram três guerras a fim de dominar o comercio lucrativo.

Outro momento, salientado por Monteiro (2001), diz respeito a época das grandes navegações, fato que marcou o comercio pois conduziu o fortalecimento dessa pratica e da moeda, culminando, portanto, na transição do sistema feudal para o capitalismo.

As exposições universais também salientam a importância do comercio num evento mundial que, segundo Pesavento (1994), demonstraram avanços tecnológicos, descobertas e invenções.

No Brasil, segundo Varotto (2006), a história do comercio está relacionada, ao povoamento do nosso território e a formação econômica e social do país.

O autor nos diz também que as lojas de rua atuais, são uma evolução do surgimento das primeiras lojas no Brasil que - por volta dos anos 1808 - devido chegada da família real ao Rio de Janeiro, houve uma intensa movimentação de navios e mercadorias relacionada a aberturas dos portos. $\mathrm{O}$ mesmo autor ainda relata que os primeiros armazéns litorâneos no período colonial, foram quase que totalmente, orientado às exportações. Como consequência surgiram lojas nas ruas próximas ao porto.

Curado (2019) ressalta outro ponto importante ao afirmar que o aumento da circulação de mercadorias, ocasionou a interação cultural e a popularização monetária.

Slater (2001) endossa a asserção, afirmando que um mercado nunca é apenas um lugar de encontro efêmero entre vendedores e compradores, mas também o local de socialização e conexão com o outro.

Diante desta explanação observa-se que o comercio sempre esteve presente na história das civilizações e revela muitos traços da natureza humana: a inclinação à socialização, o impulso aos avanços e descobertas, a diferenciação de classes, fortalecimento da moeda etc, como já mencionado.

\subsubsection{Experiências do comercio na era moderna e contemporânea}

"Nas ruas das metrópoles, o Flanêur constata que o homem moderno é vitimado pelas agressões das mercadorias e anulado pela multidão, estando condenado a vagar pela cidade como um embriagado em estado de abandono." (MASSAGLI, 2008, p. 56).

Diante da citação acima pode-se observar que, tal qual Flâneur - figura típica que emerge em decorrência da vida moderna no século XIX - nós, habitantes citadinos, presente nas ruas da cidade em pleno século XXI, permanecemos observando as atrações e distrações que a realidade do consumo proporciona e continuamos deslumbrados pela novidade e atraídos pelo poder do consumo.

De acordo com SEBRAE (2019), o comércio de rua possui alguns pontos positivos se comparada às lojas dos shoppings tais como: como custos baixos de locação, possibilidade de personalização e tamanho da fachada da loja.

Em relação aos pontos negativos do comércio de rua pode-se citar a dificuldade de acesso; ausência de vagas de estacionamento próprio das lojas de rua; além da ausência de 


\section{Revista Científica ANAP Brasil}

ISSN 1984-3240 - Volume 14, número 33, 2021

segurança que os consumidores sentem em relação ao entorno da área onde a loja está localizada.

Em se tratando de um período mais recente, as últimas décadas do século $\mathrm{XX}$ foram marcadas por uma proliferação dos shopping centers como locais de comercialização de produtos, serviços - por aglomerarem diversos serviços num só local - assim como permitir a socialização entre as pessoas e por oferecerem acesso facilitado ao estacionamento, o que transmite e uma sensação de segurança aos consumidores.

Ainda sobre os shopping centers, uma pesquisa realizada em 2004 por Andrade; De Oliveira e Antonialli (2004), revelou que 45,2\% de pessoas visitam o shopping de 2 a 3 vezes por mês e que $0,4 \%$ frequentam todos os dias.

Outra pesquisa realizada pela Abrasce (2006), revelou o perfil dos consumidores que utilizam os shopping centers, como mostra o (Gráfico 1)

Gráfico 1: Perfil do consumidor de shopping centers

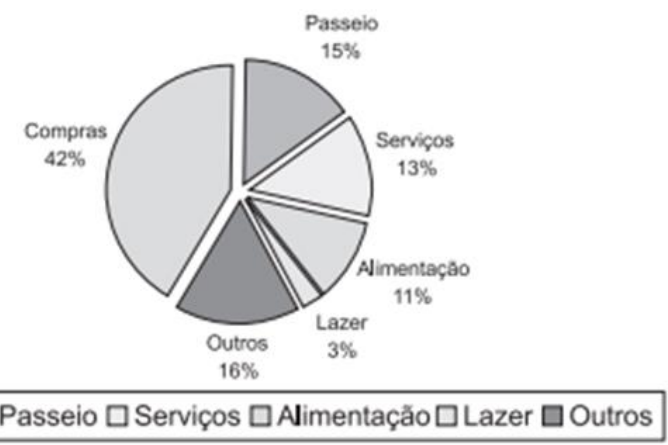

Fonte: Abrasce (2006).

Analisando os dados de ambas as pesquisas nota-se que os shopping centers são visitados com frequência por pessoas atraídas, principalmente, pelo poder catalisador do comercio.

É importante salientar que diante do surgimento dos shopping centers, as lojas de rua tiveram que se adequar à nova realidade e passaram a disputar a preferência dos consumidores.

Mais recentemente outra mudança aconteceu no setor. Dada a crescente influência da revolução digital em nossas vidas, uma nova ordem econômica de redes de conexão entre consumidor e lojas tem-se estabelecido: a compra online.

Neste sentido, uma pesquisa IBOPE (2019) mostra que no ano 2000 apenas 0,93\% de pessoas declararam realizar algum tipo de compra online em um mês no Brasil, enquanto em 2019, este número saltou para $16 \%$.

Nota-se com isso que o elemento propulsor dessa revolução, a internet, vem modificando hábitos de compra e consumo dos clientes dentre elas o estilo de compra, como afirma Galindo (2008, p. 32): “os consumidores estão mudando, a mídia está mudando, a sociedade está mudando, as empresas estão mudando, as tecnologias estão em constante mudanças, logicamente com os processos comunicativos [...] não seria diferente."

Diante disso Hortinha (2001, p. 45) afirma que a Internet possibilitou o aumento da velocidade nas transações, o fim das distâncias físicas, a compreensão do tempo e a opção de novos canais de compra.

Por outro lado, o espaço virtual, compreende o tempo de conexão que o consumidor se dedica a busca do produto e - isso não leva mais que 15 minutos - em cada loja virtual 
acessada. Por essa rapidez no tempo de conexão do consumidor e a loja virtual pode-se afirmar que este espaço se configura como um não-lugar.

Sobre o termo Lugar e Não- Lugar na Arquitetura, (ABBUD, 2006, p. 24) nos diz:

\footnotetext{
Lugar é todo aquele espaço agradável que convida ao encontro das pessoas ou ao nosso próprio encontro. Ele estimula a permanecer e praticar alguma atividade e o Não-lugar é espaço que une dois lugares. É sinônimo de passagem, algo feito para ligar e não permanecer, [...] pode ser um espaço para ser visto de fora e até ter mais importância do que o lugar.
}

Diante do exposto pode-se aplicar o conceito de lugar e não lugar em relação às lojas físicas e lojas online respectivamente pois, na loja física observa-se uma relação estreita consumidor e produto: Inicialmente o comprador vai até a loja, pede o produto, o produto é manuseado e o consumidor - imerso no ambiente que explora o produto de maneira incisiva, sentindo a textura do produto, a temperatura da loja, o cheiro, observa a opções de cores e formas de se usar o produto, etc. - desta forma, estabelece uma relação estreita com o produto. Em contrapartida, na loja virtual, essa relação estreita inexiste. Em vista disso, as experiências antes vivenciadas em lojas físicas cedem espaço às experiências mais superficiais.

A superficialidade da relação que se estabelece entre consumidor e produto durante a compra virtual se opõe grandemente à experiencia de compra em lojas físicas.

É importante ressaltar diante disso o poder de comunicação que o produto estabelece com o consumidor, ou seja, a relação entre o produto e o consumidor, na loja física, é estreita e isso facilita para que a compra do produto seja efetivada.

Diante disso, no que tange às lojas físicas, nota-se que é necessário adotar estratégias para atrair, estimular, sensibilizar e induzir o consumidor à efetivação da compra. Desta forma surgem novas tratativas comerciais na tentativa de manter os compradores para as lojas físicas assim como conquistar novos consumidores com isso novos termos e espacialidades surgiram: Lojas conceito, pontos de venda e visual merchandising, como será visto adiante.

Vale ressaltar também que em 2020 houve uma intensificação do comercio online, e esta foi alavancada exponencialmente devido à imposição de medidas mais restritivas de isolamento social que a pandemia da Covid-19 ocasionou, o que fez com que o setor comercial - mais especificamente a arquitetura comercial - fosse impulsionada a passar por uma nova reestruturação.

O dinamismo das relações comerciais e as diversas transformações do consumo, contribuíram para a formação de diferentes comportamentos dos usuários, afetando hábitos de consumo e identidade ou característica do público alvo.

Neste período, segundo dados retirados do índice (MCC-ENET, 2020) - desenvolvido pelo Comitê de Métricas da Câmara Brasileira de Comércio Eletrônico (camara-e.net) - em parceria com o Movimento Compre e Confie, no mês de abril de 2020, houve um aumento de 98\% no número de vendas pelo comércio eletrônico no Brasil em relação a 2019.

Observa-se diante deste desmedido avanço que as formas de comercio e principalmente a arquitetura comercial está envolvida diretamente com as mudanças sofridas pela sociedade como um todo.

\subsection{Cenário 1: a arquitetura dos sentidos}




\section{Revista Científica ANAP Brasil}

ISSN 1984-3240 - Volume 14, número 33, 2021

A arquitetura comercial é movida pela novidade. Isso é intensificado ainda mais pela sociedade em que vivemos, como descrita por Bauman (2004), onde o autor atrela o sentido da palavra "liquidez" ao estado da sociedade contemporânea.

O autor utiliza-se do termo "liquidez" para se referir a relação entre as pessoas, aos estilos de vida, às crenças e convicções a qual estamos inseridos atualmente. Assim conclui-se que, assim como nossa sociedade se apoia na liquidez para as mais diversas questões da atualidade, também o setor comercial o faz, e de forma ainda mais intensa pois o consumo se alimenta sempre do novo, do mais atual. Isso atribui ao setor comercial uma instabilidade, transitoriedade.

Atrelado a ideia de liquidez, as chamadas loja-conceito ou flagship stores são espaços importantes de serem analisadas como exemplos que tentam estreitar e aproximar a experiencia do consumidor com o produto, como segue:

\footnotetext{
As primeiras lojas-conceitos, inauguradas no final da década de 90, na Europa, utilizam-se do termo flagship store. A palavra flagship refere-se a uma terminologia náutica, que compreende o navio que lidera os demais e em que se acha embarcado o comandante cujas ordens os demais navios deverão seguir... É essa definição mais ampla que define a utilização do termo para a indústria de varejo. (PINTO,2015, p.85)
}

Sendo assim, as lojas-conceito - ou flagship store - despontam como novidades no setor, se constituindo como "o espaço sensorial da marca, onde todas as suas manifestações falam a mesma língua e permitem uma relação direta com o cliente, através dos sentidos". (PLASCAK, 2008, p.5).

Sobre o outro termo citado, Aguiar (2016, p.160) é pragmático ao afirmar que o "ponto de venda é a interface entre consumidor e a marca". Ainda sobre este espaço, (JANJAR, 2010); (LEMOINE, 2003) acrescentam que este local por estar em grande contato com consumidor, influencia diretamente na tomada de decisão, no volume de compra e a satisfação do cliente durante a visita.

Neste sentido vale ressaltar também o termo Visual Merchandising que segundo BLESSA, (2001, p. 22) compreende:

\footnotetext{
Técnica de trabalhar o ambiente do ponto de venda criando identidade e personificando decorativamente todos os equipamentos que circundam os produtos. O Merchandising Visual usa o design, a arquitetura e a decoração para aclimatar, motivar e induzir os consumidores à compra.
}

A partir da explicação acima entende-se que visual merchadising concerne a identidade, linguagem visual e marketing utilizados no sentido de valorizar o produto e atrair clientes.

O elo de ligação dos três conceitos é nítido: a sinestesia, todos aplicados no sentido de atrair a atenção do consumidor. Neste sentido Levy e Weitz (2000) apontam três pontos que devem ser contemplados num projeto comercial para atrair clientes-alvo: 


\section{Revista Científica ANAP Brasil}

ISSN 1984-3240 - Volume 14, número 33, 2021

\footnotetext{
- Influência nas decisões de compra: Compreender como se dá a dinâmica da compra após a entrada do cliente na loja. A partir disso, buscar a melhor solução para disposição das mercadorias em locais estratégicos...

- Produtividade de espaço: Avaliar quantitativamente as vendas geradas por cada metro quadrado da loja.
}

Ainda sobre o ambiente do ponto comercial, Blessa (2001, p. 18) acrescenta:

"A atmosfera refere-se o design de um ambiente por meio de comunicação visual, iluminação, cores, músicas, aromas para estimular as respostas emocionais e de percepção dos clientes que, ao final, poderão afetar seu comportamento de compra".

Nota-se diante desta breve explanação sobre conceitos que da arquitetura comercial na atualidade no qual o homem está inserido - o ambiente - revela-se e se comunica diretamente através dos sentidos.

Pode-se assumir com isso que a atribuição das dimensões sensoriais a arquitetura comercial, está ligada as estratégias de persuasão utilizadas no ambiente comercial.

Ao observarmos esses pontos verificamos a veracidade da afirmação de Veríssimo (2009), ao ressaltar que a arquitetura dos sentidos faz a fusão das dimensões sensoriais junto a vivência do homem, trazendo significados e alterando a forma de uso dos espaços. Assim, o encontro entre a arquitetura e o usuário, segundo (FUÃO, 2004), acaba sendo uma experiência individualizada, a qual pode ser modificada em decorrência da constante vivência.

Lindstrom (2007) e Aguiar (2016) atestam que quanto maior forem os estímulos e memórias sensoriais provocadas pelo espaço, maior será a adesão do consumidor a marca. Essa questão é fundamental também para a relação com o objeto, pois este passa a ser determinante na motivação da compra e estando ligado a busca de novas experiências e o desejo de satisfação.

Por essa razão vale salientar o ponto de vista de Campbell (2001, p. 130) que é bastante assertivo ao afirmar: "O consumidor moderno desejará um romance em vez de um produto habitual porque isso o habilita a acreditar que sua aquisição, e seu uso, podem proporcionar experiências que ele, até então não encontrou na realidade."

Observa-se diante do exposto que a configuração do ambiente - temperatura, cores, etc - atrelada a experiência individual das pessoas contribuem e permitem o acesso a dimensões psicológicas e sociais do consumo.

Newsom, Collier e Olsen (2009); Serrentino (2016), complementam que umas das táticas atualmente usadas consiste em oferecer uma experiência de compra diversa e agradável ao consumidor e que, para atingir o público-alvo, alguns comerciantes apelam para a estruturação física e espacial da loja. Neste contexto Azambuja (1997) salienta que o edifício passa a ser avaliado/discutido enquanto espaço "vivencial", pois está sujeito à ocupação, leitura, reinterpretação e/ou modificação pelos usuários.

Observa-se diante desta explanação que as lojas-conceito ou flagship store se baseiam na comunicação entre a marca e o usuário, e que o fator novo que as lojas-conceito trazem consigo é a nova forma de comunicação com os consumidores, que ocorre através do estabelecimento de uma linguagem, associado à sinestesia, como pode-se observar na (Figura 2). 


\section{Revista Científica ANAP Brasil}

ISSN 1984-3240 - Volume 14, número 33, 2021

Figura 2 - Interior da loja Gucci Wooster

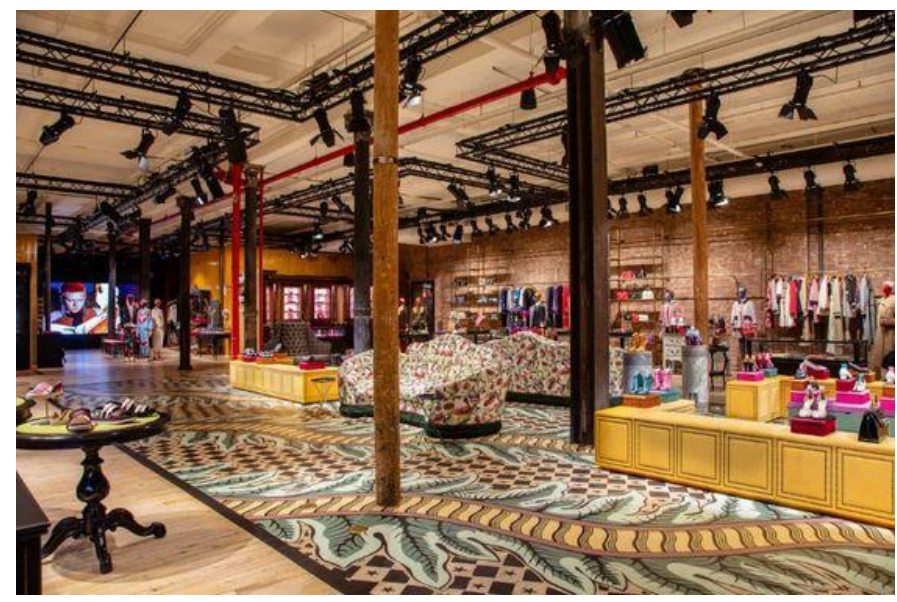

Fonte: Gucci... (2018)

Ao observar a (Figura 2) nota-se claramente o distanciamento entre o comercio tradicional - que foca na funcionalidade e nos benefícios dos produtos - e a loja conceito, que é o ponto de venda organizado de forma a promover a experiência de lugares.

Schmitt (2002), acrescenta que a loja-conceito promove a experiência que é o resultado do encontro e da vivência de situações que são estímulos criados para os sentidos. Segundo o mesmo autor, essa vivência tem o poder de conectar as intenções de uma marca com o estilo de vida do cliente uma vez que "as experiências geram valores sensoriais, emocionais, cognitivos, comportamentais e de identificação, que substituem os valores funcionais" (SCHMITT, 2002, p. 41)

Diante disso observa-se que os consumidores são atraídos pela nova forma de comunicação dos espaços, que são arranjados de forma a oferecer experiências reais e sensoriais através da provisão de ambientes que proporcionam bem-estar e os envolvem numa experiencia do lugar.

Frederico et al. (2014) salienta ainda que as lojas conceito, são projetadas e geridas para criar atmosfera e experiência de compra que venham a transmitir, integralmente, 0 posicionamento desejado pela marca através dos estímulos de todos os sentidos.

Em meio a era da internet nota-se a importância das lojas-conceito enquanto experiencia de imersão na marca, uma vez que o comercio online priva o usufruto do ambiente em lojas menores dispostas na cidade e em shoppings.

\subsection{Cenário 2: o comercio online e a pandemia}

Uma pesquisa feita pela Criteo (2020) mostra que nos Estados Unidos na primeira quinzena de março, as vendas em lojas físicas despencaram $46 \%$, enquanto as vendas online cresceram em $58 \%$.

Desse modo, observa-se que as empresas que queiram obter bons resultados no mercado atual precisam utilizar novas táticas para atingir seu público.

Ponderando sobre as mudanças ocorridas recentemente, Turban, Mclean e Wetherbe (2004) apontam que os principais benefícios do comercio eletrônicos para os consumidores foram: Produtos e serviços mais baratos - possibilitados pela facilidade de comparação de preços de mercado; escolhas mais diversificadas - por passarem a ter acesso a mais fornecedores; 


\section{Revista Científica ANAP Brasil}

ISSN 1984-3240 - Volume 14, número 33, 2021

comodidade de horário - pois o acesso pode ser efetuado a qualquer hora do dia. Ainda sobre essa intensificação de compras online, Torres (2018), salienta que antes da pandemia as compras feitas pela internet utilizam efetivamente a tecnologia digital para alcançar novos clientes, fidelizar os atuais e afirma que esse novo modo de compra foi aderido rapidamente pelos brasileiros.

Se opondo à essas vantagens acima observadas vale salientar que a intensificação do comercio eletrônico promove o distanciamento do consumidor e das lojas físicas e isso nos faz pensar na importância da conexão do consumidor com a marca, a priori.

Outro ponto que merece destaque diz respeito a um levantamento da Confederação Nacional do Comércio de Bens, Serviços e Turismo (CNC, 2021) e publicado no próprio site, mostra que mais de 75 mil lojas fecharam as portas no Brasil, no primeiro ano da pandemia de covid-19. O mesmo site afirma que o ramo que mais perdeu unidades foi o de vestuário, calçados e acessórios. Este fato é importante pois, nesta pesquisa, o ramo de vestuário foi o setor analisado. Outro ponto que foi salientado pelo mesmo site é que a grande dependência do consumo presencial no setor de vestuário ocasionou esta queda, isso ressalta ainda mais a importância da experiencia de compra na sua efetivação.

Neste sentido Sheth, Eshghi e Krishnan, (2002), relatam também que muitos consumidores consideram a experiência de compras em lojas física uma fonte de prazer e uma oportunidade de interação social, o que acaba sendo conflitante com a realidade virtual atualmente praticada.

Uma pesquisa realizada pela NZN Intelligenc (2020) mostrou que em agosto de 2020, também neste mesmo sentido, levou a $74 \%$ das pessoas a preferirem a loja física ao invés da compra online por poderem provar a peça antes de levar para casa. Nota-se com isso uma resistência por parte do consumidor em aderir a modalidade online, contudo se esse período de estratégias mais restritivas no combate a pandemia se prolongar é possível que pessoas que nunca utilizaram a internet como meio de compra passe a ter sua experiencia em breve, podendo ser possível até transformar isto num novo hábito.

Uma pesquisa feita por Simonsen (2019) em 2019, mostrou que na realidade as lojas físicas, não estão propensas a desaparecer, pois mais de $76 \%$ dos compradores daquele período, gostam de comprar tanto em loja física, como em loja virtual.

Observa-se assim que o setor ainda está se adequando a este novo cenário e que muitas mudanças ainda podem ocorrer, principalmente se o período de espera pela vacina contra a Sars - Cov 2, se prolongar. Diante deste panorama as pessoas não terão outra alternativa senão adotar a forma de comercio online, por essa razão o setor tende a se desenvolver ainda mais nos próximos meses.

$\mathrm{Na}$ busca de um entendimento e ponderação acerca do exposto acima é importante salientar a asserção:

"A experiência de compra é o conjunto das percepções que um consumidor desenvolve ao interagir com uma loja durante as fases de pesquisa, compra e até a relação pósvenda". (SEBRAE, 2017).

Tal asserção valoriza a experiencia de compra como um processo longo onde as etapas deste processo podem ser salientadas, como segue:

- A pesquisa - lojas físicas, shopping centers, lojas de rua ou shopping online a fase da pesquisa é uma etapa importante para o consumidor enquanto fase de tomar conhecimento sobre o que tem disponível no mercado acerca do objeto desejado; 


\section{Revista Científica ANAP Brasil}

ISSN 1984-3240 - Volume 14, número 33, 2021

- A efetivação da compra - diante do atual contexto da pandemia - e a intensificação do comercio online - esta etapa foi a mais prejudicada no que concerne a impossibilidade de manusear o produto, a experimentação e vivencia da ambientação da loja, a pratica da socialização, etc.

O comercio online é pragmático e célere pois não permite que todos os sentidos do consumidor sejam ativados no momento da compra. Esse fator priva o consumidor do "prazer" que Sheth, Eshghi e Krishnan (2002) salientaram acima. Além disso o consumidor acaba sendo privado do estabelecimento de uma relação mais estreita e aprofundada com a marca, como ocorre no nas lojas físicas;

- Pós-venda - o pós venda é outro ponto importante do processo de compra como atesta o site Sebrae (2018) ao afirmar que oferecer serviços e vantagens depois da compra é uma estratégia para fidelização de clientes.

Neste sentido tanto a fase de compra física como a compra online devem se esmerar em oferecer ao cliente está atenção e cuidado no pós venda, e isso pode ser utilizado como uma ferramenta de fidelização de clientes.

A afirmação Abbud (2006) acrescenta a questão um ponto importante a ser considerado, ao afirmar que o espaço físico pode ser medido matematicamente; já o espaço psicológico é percebido apenas pelas sensações.

Diante disso pode-se observar que as sensações não estão vinculadas somente aos cinco sentidos humanos a saber: olfato; paladar; visão; tato e audição, mas também a percepção e leitura individual do consumidor sobre a identidade, confiabilidade da marca. Neste sentido a memória sensorial do consumidor pode ser ativada - de forma a conduzir o consumidor à efetivação da compra ou à desistência dela - e isso pode diferenciar as experiências sensoriais do consumidor frente uma marca ou para a outra.

Esse ponto colabora também com a aproximação do consumidor à identidade da marca, assim como a fidelização deste à marca, o que constitui uma relação profunda e estreita da marca com o consumidor.

\section{CONCLUSÃO}

Essa pesquisa buscou através de uma abordagem histórico-investigativa se aprofundar, refletir e analisar a arquitetura comercial no intuito de entender a aceleração que a pandemia ocasionou no setor - diante da aceleração de um processo que estava em progresso - o comercio online frente a postura determinante da arquitetura sinestésica que se apoia profundamente na experencia sensorial dos espaços como elementos indutores da efetivação da venda.

Ao longo da pesquisa pôde-se observar que a arquitetura comercial se comunica, é linguagem no sentido de passar conceitos da marca, experiencias de compra e que diante do momento atual de pandemia essa comunicação - enquanto experimentação espacial - tem sido prejudicada. Contudo notou-se no decorrer desta pesquisa, que o setor sempre se adapta às demandas da sociedade, neste sentido sugere-se que talvez um caminho a ser explorado seja considerar toda a experiencia da compra: a pesquisa, a efetivação da compra e o pós venda, como fases necessárias à conclusão do processo de compra e que no momento atual a fase da pesquisa e do pós venda podem ser melhor explorados.

Se por um lado, durante a fase de efetivação da compra, a experimentação da marca em toda sua amplitude não pode ser vivenciada em sua plenitude - devido ao distanciamento imposto devido ao distanciamento - o pós venda pode ser utilizado para suprir essa deficiência pois, como observado, o importante parece ser a relação estreita de identidade da marca com o consumidor que deve estar sempre em evidencia, no intuito de reforçar a assinatura e postura da marca, objetivando a efetivação da venda e a fidelização do cliente. Pensando nisso, entende- 


\section{Revista Científica ANAP Brasil}

ISSN 1984-3240 - Volume 14, número 33, 2021

se que não basta apenas vender produtos, mas gerar uma experiência única ao cliente, inclusive no sentido de salientar a confiabilidade e a segurança que a marca oferece.

Neste sentido pode-se concluir que dificilmente tendências para o setor no período pós pandemia podem ser traçadas pois estamos no meio de um processo, que por si só tem natureza volátil, porém pode-se focar no período de pesquisa e no pós venda com campos a serem mais valorizadas e a partir disso outras pesquisas podem ser realizadas no sentido de se buscar alternativas para estas duas fases da compra - pesquisa e pós venda - no sentido de oferecer experiências repletas de significados.

\section{REFERÊNCIAS}

ABBUD, B. Criando Paisagens: Guia de Trabalho em Arquitetura Paisagística. 4. ed. Bela Vista: Senac São Paulo, 2006.

ABRASCE. Associação brasileira de shopping centers. Radiografia do Setor. São Paulo: ABRASCE, 2006.

AGUIAR, K. P. de. Ambientes comerciais e a influência do design visual. 2016. Dissertação (Mestrado em Design e Arquitetura) - Faculdade de Arquitetura e Urbanismo, Universidade de São Paulo, São Paulo, 2016. Disponível em: https://teses.usp.br/teses/disponiveis/16/16134/tde-16022017-123447/pt-br.php. Acesso em: 18 fev. 2021.

ANDRADE, D.; DE OLIVEIRA, J. e ANTONIALLI, L. O perfil de clientes de um shopping center: um estudo exploratório com consumidores do interior. Organizações Rurais \& Agroindustriais, Lavras, v. 6, n. 2, p. 91-105, jul./dez. 2004. Disponível em: http://revista.dae.ufla.br/index.php/ora/article/view/222/219. Acesso em: 23 mar. 2020.

ASSOCIAÇÃO BRASILEIRA DE COMERCIO ELETRÔNICO. Faturamento do e-commerce cresce $56,8 \%$ neste ano e chega a R\$ 41,92 bilhões. São Paulo, ABCOMM, 21 set. 2020. Disponível em:

https://abcomm.org/noticias/faturamento-do-e-commerce-cresce-568-neste-ano-e-chega-a-r-4192-bilhoes/. Acesso em: 28 fev. 2021.

ATHENS, E. Building Around the Mind. Scientific American Mind. v. 20, n. 2, pp. 52-59, April/May/June 2009.

AZAMBUJA, G. Psicologia e Arquitetura: em busca do locus interdisciplinar. 1997. Artigo (Estudo de Psicologia) Universidade Federal do Rio Grande do Norte, RN, 1997. Disponível em:

http://www.scielo.br/pdf/epsic/v2n2/a09v02n2.pdf. Acesso em: 26 jun 2019.

BAUMAN, Z. Amor Líquido: sobre a fragilidade dos laços humanos. Rio de Janeiro: Jorge Zahar Editor, 2004.

BLESSA, R. Merchandising no ponto-de-venda. São Paulo: Atlas, 2001

CAMPBELL, C. A ética romântica e o espírito do consumismo moderno. Rio de Janeiro: Rocco, 2001.

CNC. Confederação Nacional do Comércio de Bens, Serviços e Turismo. Com pandemia, 75 mil lojas fecharam as portas em 2020. [S.l]: CNC. 03 jan. 2021. Disponível em: http://www.cnc.org.br/editorias/economia/noticias/compandemia-75-mil-lojas-fecharam-portas-em-2020. Acesso em: 18 mar. 2020.

COMERCIO. In: DICIONÁRIO da língua portuguesa. Lisboa: Priberam Informática, 2019. Disponível em: https://dicionario.priberam.org/COMERCIO. Acesso em: 8 mar. 2019.

CONSELHO NACIONAL DE EDUCAÇÃO (BRASIL). Resolução no 2, de 17 de junho de 2010. Institui as Diretrizes Curriculares Nacionais do curso de graduação em Arquitetura e Urbanismo. Brasília, DF: Ministério da Educação, 2010. Disponível em: http://portal.mec.gov.br/index.php?option=com_docman\&view=download\&alias=5651rces002-10\&Itemid=30192. Acesso em: 23 mar. 2020.

CONDE, D.; MAFRA, F.; CAPPELLE, M. Escambo. Revista Interdisciplinar de Gestão Social, Salvador, v. 3, n. 1, jan./ abr. 2014. Disponível em: https://periodicos.ufba.br/index.php/rigs/article/view/9169/11599. Acesso em: 10 mar. 2021.

CRITEO. [PESQUISA] Tendências de consumo em tempos de coronavírus: eletrônicos, mercado pet e muito mais. Criteo. [S.I.] 2020. Disponível em: criteo.com/br/blog/tendencias-de-consumo-em-tempos-de-coronavirus/. Acesso em: 10 set. 2020. 


\section{Revista Científica ANAP Brasil}

ISSN 1984-3240 - Volume 14, número 33, 2021

CRUVINEL, I. Marketing digital em tempos de pandemia digital marketing in pandemic times. Gestão \& Tecnologia Faculdade Delta, Goiânia, v. 1, jan./ jun. 2020. Disponível em:

http://faculdadedelta.edu.br/revistas3/index.php/gt/article/view/57/44. Acesso em: 07 set. 2020.

CURADO, A. Comércio - conceito, onde surgiu, como se desenvolveu e atualidades. In: Conhecimento Científico. [S.I.]: 2019. Disponível em: https://conhecimentocientifico.r7.com/comercio-conceito-onde-surgiu-como-sedesenvolveu-e-atualidades/. Acesso em: 09 set. 2020.

DE MOURA, F. Diplomacia no mundo antigo: os tratados de cooperação militar e mercantil entre roma e cartago. 509-279 a. C. 2008. Disponível em: http://www.neauerj.com/Nearco/arquivos/numero10/13.pdf. Acesso em: 10 mar. 2021

FERRARI, M. Pandemia mudou padrões de consumo e interação social, diz presidente da Google. CNN Brasil, São Paulo, 07 jul. 2020. Disponível em: https://www.cnnbrasil.com.br/business/2020/07/04/pandemia-mudou-padroesde-consumo-e-interacao-social-diz-presidente-do-google. Acesso em: 19 mar. 2020.

FREDERICO, E.; CANTAFARO, R.; AYDAR e F.; SHINZAKI, A. Valor, satisfação e recomendação espontânea para uma marca varejista. Revista Brasileira de Marketing, v. 13, n. 6, p. 107-123, 2014.

FUÃO, Fernando Freitas. O sentido do espaço. Em que sentido, em que sentido? - 1a parte. Arquitextos, São Paulo, ano 04, n. 048.02, Vitruvius, mai. 2004. Disponível em:

https://vitruvius.com.br/revistas/read/arquitextos/04.048/582. Acesso em: 20 mar. 2021.

GALINDO, D. Comunicação mercadológica - uma visão multidisciplinar. São Bernardo do Campo: Universidade Metodista de São Paulo, São Paulo, 2008.

GUCCI has a bold new store in SoHo, New York [PHOTOS]. In: AD: Architectural Digest India. Mumbai, 23 May 2018. Disponível em: https://www.architecturaldigest.in/content/gucci-bold-new-store-soho-new-york-photos/. Acesso em: 19 fev. 2021.

HORTINHA, J. e-marketing: Um Guia para a Nova Economia. Lisboa: Edições Silabo, 2001.

IBOPE, Instituto Brasileiro de Opinião Pública e Estatística. Consumo e Sociedade: um raio-x de duas décadas, São Paulo, 28 out. 2019.

INSTITUTO DE ENSINO E PESQUISA. Pandemia influencia o comportamento das marcas nas mídias sociais. São Paulo, INSPER, 25 mai. 2020. Disponível em: https: https://www.insper.edu.br/noticias/midias-sociais-pandemiamarcas/. Acesso em: 08 set. 2020.

JANJAR, C. Experiências no ponto de venda: a construção de lojas conceito como diferencial competitivo. 2010. Monografia - (Faculdade de Biblioteconomia e Comunicação), Universidade Federal do Rio Grande do Sul. Porto Alegre. 2010. Disponível em:

https://www.lume.ufrgs.br/bitstream/handle/10183/27893/000768007.pdf?sequence=1\&isAllowed=y Acesso em: 13 mar. 2021.

LEAL, P. A evolução do trabalho humano e o surgimento do Direito do Trabalho. In: Jus. 2014. Disponível em: https://jus.com.br/artigos/32198/a-evolucao-do-trabalho-humano-e-o-surgimento-do-direito-do-trabalho. Acesso em: 25 out. 2020.

LEMOINE, J. Avers une approche globale de látmosphère du point de vente. Revue Française du Marketing, n. 1944/5, pp.83-101, Septembre, 2003.

LEVY, M.; WEITZ B. Administração de varejo. São Paulo: Atlas, 2000.

LINDSTROM, M. Brandsense: a marca multissensorial. Porto Alegre: Bookman, 2007.

Manual do Arquiteto e Urbanista / Conselho de Arquitetura e Urbanismo do Brasil. 1. ed. - Brasília: CAU/BR, 2016.

MASSAGLI, S. Homem da multidão e o flâneur no conto “O homem da multidão” de Edgar Allan Poe. Terra Roxa e Outras Terras: Revista de Estudos Literários, Londrina, v. 12, p. 55-65, jun. 2008.

MCC-ENET. Índice de Vendas Online. In: MCC-ENET. [S.I.], 2020. Disponível em: 


\section{Revista Científica ANAP Brasil}

ISSN 1984-3240 - Volume 14, número 33, 2021

https://www.mccenet.com.br/indice-de-vendas-online. Acesso em: 18 mar. 2021

MONTEIRO, N. As grandes navegações e o descobrimento do brasil. Revista da Escola Superior de Guerra, Rio de Janeiro v. 1, n. 40, p. 188-209, dez 2020.

NEWSOM M.; COLLIER, D.; OLSEN E. Using “biztainment" to gain competitive advantage. Business Horizons, v. 52, n. 2, p. 167-176, 2009

NZN Intelligence. Compra online já é preferência de 74\% dos consumidores brasileiros. In: Intelligence. [S.I]: 2020. Disponivel em: https://intelligence.nzn.io/compra-online-ja-e-preferencia-de-74-dos-consumidoresbrasileiroslevantamento-realizado-pelo-nzn-intelligence-aponta-que-habitos-de-consumo-vem-mudando-entre-osbrasileiros/. Acesso em: 18 mar. 2021.

PLASCAK, N. A Experiência sensorial da marca pós-moderna. In: XXXI Congresso Brasileiro de Ciências da Comunicação, 2008, Natal. Disponível em: http://www.intercom.org.br/papers/nacionais/2008/resumos/R3-11531.pdf. Acesso em: 11 mar. 2021.

PESAVENTO, S. J. Imagens da nação, do progresso e da tecnologia: a Exposição Universal de Filadélfia de 1876. In: 1994, São Paulo. Anais do Museu Paulista: História e Cultura Material. São Paulo: UFRGS, 1994. v. 2, n. 1, p. 151 168. Disponível em: https://www.scielo.br/pdf/anaismp/v2n1/a11v2n1.pdf. Acesso em: 10 mar. 2021.

PINTO, R. Lojas-Conceito como Fortalecimento da experiência do consumidor no ponto de venda.2015. Trabalho de Conclusão de Curso. (Graduação Publicidade Propaganda) Universidade Federal do Paraná. Setor de Artes, Comunicação e Design, Paraná, 2015

PLAZA, J. Tradução intersemiótica. 2. reimp. São Paulo: Perspectiva, 2003.

SCHMITT, B. H. Marketing Experimental. São Paulo: Nobel, 2002.

SEBRAE. Como escolher a melhor localização para o seu negócio. [S.I]: SEBRAE, 2019. Disponível em: https://www.sebrae.com.br/sites/PortalSebrae/artigos/como-escolher-melhor-ponto-comercial-para-seunegocio,d9d89e665b182410VgnVCM100000b272010aRCRD. Acesso em: 09 mar. 2020.

SEBRAE. Consultoria: Pós-vendas. [S.I.]: SEBRAE, 2018. Disponível em: https://www.sebrae.com.br/sites/PortalSebrae/ufs/ms/programas/consultoria-posvendas,4a25a978c3fc5610VgnVCM1000004c00210aRCRD. Acesso em: 05 set. 2020.

SEBRAE. O que é a experiência de compra? [S.I.]: SEBRAE, 2017. Disponível em: https://blog.sebrae-sc.com.br/oque-e-experiencia-de-compra/. Acesso em: 05 set. 2020.

SERRENTINO, A. Varejo e Brasil: reflexões estratégicas. São Paulo: [s.n.], 2016.

SHETH, J. N.; ESHGHI, A.; KRISHNAN, B.C. Marketing na Internet. Bookman, 2002.

SIMONSEN, M. The Store of the Future. My total retail. Philadelphia. 12 Apr. 2019. Disponível em: https://www.mytotalretail.com/article/the-store-of-the-future/. Acesso em: 13 mar. 2021.

SLATER, D. Cultura do consumo e modernidade. São Paulo: Livraria Nobel, 2001.

TORRES, C. A bíblia do marketing digital: tudo o que você queria saber sobre marketing e publicidade na internet e não tinha a quem perguntar. São Paulo: Novatec Editora, 2018.

TURBAN, E.; MCLEAN, E. e WETHERBE, J. Tecnologia da informação para gestão: Transformando os Negócios na Economia Digital, 3. Ed. Porto Alegra, Bookman, 2004.

VAROTTO, L. F. História do varejo. GV executivo, São Paulo, v. 5, n. 1, p. 86-90, fev./ abr. 2006. Disponível em: https://bibliotecadigital.fgv.br/dspace/bitstream/handle/10438/26526/34379-65700-1-PB.pdf. Acesso em: 11 mar. 2020.

VERÍSSIMO, C. H. Arquitetura da imersão - por uma arquitetura de verdade. 2009. Trabalho de Conclusão de Curso (Graduação em Arquitetura e Urbanismo) - Faculdade de Arquitetura, Artes e Comunicação, Universidade Estadual Paulista, Bauru, 2009. 